\title{
Induction of Intercellular Adhesion Molecule-1 on Human Brain Endothelial Cells by HIV-1 gp120: Role of CD4 and Chemokine Coreceptors
}

\author{
Monique F. Stins, Donna Pearce, Francescopaolo Di Cello, Anat Erdreich-Epstein, \\ Carlos A. Pardo, and Kwang Sik Kim
}

Division of Infectious Diseases, Department of Pediatrics (MFS, DP, FD, KSK), Department of Neurology and Pathology (CAP), Johns Hopkins School of Medicine, Baltimore, Maryland; and Division of Hematology-Oncology (AE-E), Department of Pediatrics, Childrens Hospital Los Angeles, Los Angeles, California

\begin{abstract}
SUMMARY: Central nervous system dysfunction is commonly observed in children with HIV-1 infection, but the mechanisms whereby HIV-1 causes encephalopathy are not completely understood. We have previously shown that human brain microvascular endothelial cells (HBMEC) from children are responsive to gp120 derived from X4 HIV-1 by increasing expression of intercellular adhesion molecule (ICAM)-1 and vascular cell adhesion molecule-1. However, the mechanisms involved in gp120-mediated up-regulation of cell adhesion molecule expression is unclear. In the present study, we found that gp120 derived from both X4 and R5 HIV-1 induced increased expression of ICAM-1 on HBMEC, but the degree of this up-regulation differed among the various HBMEC isolates. The up-regulation of ICAM-1 was inhibited by anti-CD4 antibodies as well as by specific antibodies directed against chemokine receptors and small-molecule coreceptor inhibitors. Anti-CD4 antibodies inhibited the increase in ICAM-1 expression mediated by gp120 derived from X4 and R5 HIV-1, whereas antibodies against chemokine receptors displayed a differential inhibition depending on the source of gp120. Both X4 and R5 gp120-induced ICAM-1 expression was sensitive to pertussis toxin and involved the nuclear factor-kB pathway. These findings indicate a direct involvement of CD4 and a differential involvement of chemokine receptors in the activation of pediatric HBMEC by X4 and R5 gp120. The activation of brain endothelium of children by HIV-1 protein gp120 by way of CD4 and chemokine receptors may have implications for the pathogenesis of HIV-1 encephalopathy in the pediatric population. (Lab Invest 2003, 83:1787-1798).
\end{abstract}

$H$ IV-1 enters the central nervous system (CNS) and causes encephalopathy in AIDS patients. HIV-1 may cross the blood-brain barrier (BBB) endothelium by way of several possible mechanisms. HIV-1 may enter the CNS using the Trojan Horse mechanism by way of transmigration of HIV-1-infected monocytes (Nottet et al, 1996; Persidsky et al, 1997), absorptive endocytosis (Banks et al, 1997), macropinocytosis (Liu et al, 2002), or by directly infecting brain endothelium (Edinger et al, 1997; Moses et al, 1993; Poland et al, 1995). In addition, the brain endothelium may be activated or injured by HIV proteins (eg, gp120) and cytokines and thereby allow increased penetration of cell-free HIV or HIV-infected monocytes into the CNS (Fiala et al, 1997; Stins et al, 2001).

Although it is generally accepted that perturbations of the BBB are common in HIV-1-infected patients,

\section{DOI: 10.1097/01.LAB.0000107008.13321.C8}

Received August 19, 2003.

This study was supported by the Elisabeth Glaser Pediatric AIDS foundation PFR-77376-24 and NIH RO-1 MH 63850 to MFS and NIH RO-1 grant HL 61951 to KSK.

Address reprint requests to: Dr. Monique F. Stins, Division of Infectious Diseases, Department of Pediatrics, Johns Hopkins School of Medicine, 720 Rutland Ave, Ross 1170, Baltimore, MD 21205. E-mail: mstins@jhmi.edu the underlying mechanisms for endothelial dysfunction are unclear. Under normal conditions, the BBB efficiently forms a tight barrier between the blood and the brain, strictly regulating the passage of substances across this barrier. However, during HIV-1 infection, the endothelium of the BBB is affected by many inflammatory substances, viral proteins, viral cofactors, and viral particles originating both from the blood and the brain side, and structural and functional perturbations of the BBB may occur. Evidence for alteration of BBB function in HIV-1 encephalitis (HIVE) is commonly featured after examination of postmortem tissues (Berger et al, 2000; Petito and Cash 1992; Power et al, 1993). A direct compromise of tight junctions (eg, focal alterations in junctional markers such as ZO-1/occludin) was demonstrated in postmortem brain specimens of HIV-1 patients, in a severe combined immunodeficiency disease mouse model for HIVE, and in in vitro cell culture experiments (Persidsky et al, 2000). Additional evidence for increased permeability of the BBB was shown by the leakage of serum proteins into the brain, alteration of vessel diameter, and thinning of basal lamina (Buttner et al, 1996; Power et al, 1993; Rhodes, 1991; Weis et al, 1996).

Alterations in protein expression (eg, decrease in general glycoproteins), a specific decrease in 
P-glycoprotein, and increased cell adhesion molecule expression on the endothelium were demonstrated in human brain specimens with HIVE and in a severe combined immunodeficiency disease mice model (Buttner et al, 1996; Persidsky et al, 2000). In simian models with simian immunodeficiency virus infection, changes in protein expression were found in brain endothelium (eg, increase in vascular cell adhesion molecule [VCAM]-1 expression) (Sasseville et al, 1992) and decrease in glucose transporter expression (Mankowski et al, 1999). Endothelial activation and damage is also reflected in an increase of endothelial cell products circulating in plasma, such as soluble adhesion proteins and procoagulant proteins (eg, von Willebrand factor), soluble thrombomodulin, tissue type plasminogen activator, plasminogen activator inhibitor, angiotensin converting enzyme, and endothelin-1 (Lafeuillade et al, 1992; Rolinski et al, 1994; Schved et al, 1992; Seigneur et al, 1997).

To study the role of the brain endothelium in the pathogenesis of HIV-1 encephalopathy, we developed an in vitro model of the human BBB by isolating and culturing human brain microvascular endothelial cells (HBMEC) (Stins et al, 2001). We were the first to show that gp120 can activate HBMEC from children in up-regulation of VCAM-1, intercellular adhesion molecule (ICAM)-1, and increased monocyte transmigration (Stins et al, 1997). Other investigators have also shown the gp120-mediated induction of ICAM-1 on endothelial cells derived from different origins: lung, skin, coronary artery, and umbilical vein (Ren et al, 2002). However, the underlying mechanisms involved in gp120-mediated activation of HBMEC are unclear (eg, roles of CD4, CCR3, CCR5, and CXCR4 receptors or other nonchemokine receptors).

HIV-1 coat protein gp120 can activate a variety of cell types, such as secretion of TGF- $\beta$ by astrocytes (non-CD4 dependent) (Da Cunha et al, 1995), IL-1 $\beta$ and TNF- $\alpha$ in the rat brain (llyin and Plata-Salaman, 1997), and arachidonic acid metabolites and IL-1 by monocytes (Wahl et al, 1989), and also increase the permeability of rat brain endothelium (Annunziata et al, 1998). Gp120 also induces apoptosis in T lymphocytes (Finkel et al, 1995) and neurons (Hesselgesser et al, 1998; Lannuzel et al, 1997). Gp120 may exhibit these phenotypes by way of CD4, chemokine coreceptors, or other non-CD4 and nonchemokine receptor mechanisms (eg, substance P) (Annunziata et al, 1998). Endothelial cells are heterogeneous and differ based on the source (eg, various organs, macroversus microvessels, age, or sex) (Craig et al, 1998; Kumar et al, 1987; MacLean et al, 2001). Endothelium from the brain has been shown to display a differential panel of receptors for HIV-1 gp120, such as chemokine coreceptors (Andjelkovic and Pachter, 2000; Berger et al, 2000; Edinger et al, 1997; Mukhtar et al, 2002), sulfatide (Prasadarao et al, 1993), and CD4 (Stins et al, 2001). We showed that the gp120mediated enhancement of monocyte transendothelial migration in pediatric HBMEC was blocked by antiCD4 antibodies, indicating that CD4 in pediatric brain endothelial cells is functional and responsive to gp120. In contrast, HBMEC derived from adults is not responsive to gp120. We have previously shown the presence of CD4 in pediatric endothelial cells using four different methods (eg, RT-PCR, FACS analysis, and immunocytochemistry of isolated HBMEC and frozen brain sections) (Stins et al, 2001). However, the involvement of HIV-1 receptors such as CD4 and chemokine coreceptors in the gp120-induced ICAM-1 expression is unclear.

In this report, we examined the involvement of CD4 and chemokine coreceptors in gp120-induced ICAM-1 expression by using antibodies against CD4 and chemokine coreceptors as well as small-molecule coreceptor inhibitors (Tamamura et al, 2001) and examined the underlying signaling pathways using pertussis toxin (ptx), an inhibitor of Gi/o-protein coupled receptors such as chemokine coreceptors and Bay 11-7082, a nuclear factor (NF)-kB inhibitor.

\section{Results}

\section{Gp120 Induces ICAM Expression on HBMEC}

We previously showed that X4 gp120 can induce ICAM-1 expression on pediatric HBMEC. Here, we examined the effects of different gp120 concentrations and the kinetics of ICAM- 1 expression in pediatric HBMEC. HBMEC were incubated with 0.01 to 1 $\mu \mathrm{g} / \mathrm{ml}$ gp120 derived from X4 HIV-1 for up to 72 hours. Figure $1 \mathrm{~A}$ shows that after 24 hours of treatment, gp120 $(0.1 \mu \mathrm{g} / \mathrm{ml})$ could increase ICAM-1 expression by $20 \%$, and ICAM-1 up-regulation up to $170 \%$ was achieved with $0.5 \mu \mathrm{g} / \mathrm{ml}$ of gp120. No up-regulation of ICAM-1 expression was observed with gp120 concentrations at $0.01 \mu \mathrm{g} / \mathrm{ml}$. TNF- $\alpha(10 \mathrm{ng} / \mathrm{ml})$, which was used as a positive control, increased ICAM-1 expression by $60 \%$. Figure $1 \mathrm{~B}$ shows that a maximal expression of ICAM-1 was achieved after 24 hours of exposure to gp120, and ICAM-1 expression decreased after 48 to 72 hours of incubation. Inclusion of polymyxin B did not affect gp120-induced ICAM-1 expression, whereas preabsorption with anti-gp120 antibodies abrogated the gp120-mediated increase in ICAM-1 expression (not shown), indicating that this gp120 effect was not mediated by any contaminating endotoxin in the gp120 preparation and was specific to gp120.

We next examined whether gp120 derived from R5 HIV-1 would be equally effective as gp120 derived from X4 HIV-1. For this, we tested more than 10 different $\mathrm{HBMEC}$ isolates, and Figure 2, $\mathrm{A}$ to $\mathrm{C}$, shows typical patterns of the increase in ICAM-1 expression induced by gp120 $(0.1 \mu \mathrm{g} / \mathrm{ml})$ derived from R5 and X4 HIV-1 in HBMEC derived from three different children. We found that X4 gp120 can consistently increase ICAM-1 expression, whereas the effects of M-tropic gp120 on ICAM-1 expression were variable. Of interest, one HBMEC isolate failed to exhibit ICAM-1 up-regulation in response to R5 gp120 (Fig. 2C). It is not clear why the responses of the HBMEC to R5 gp120 differ from those of X4 gp120. 
A

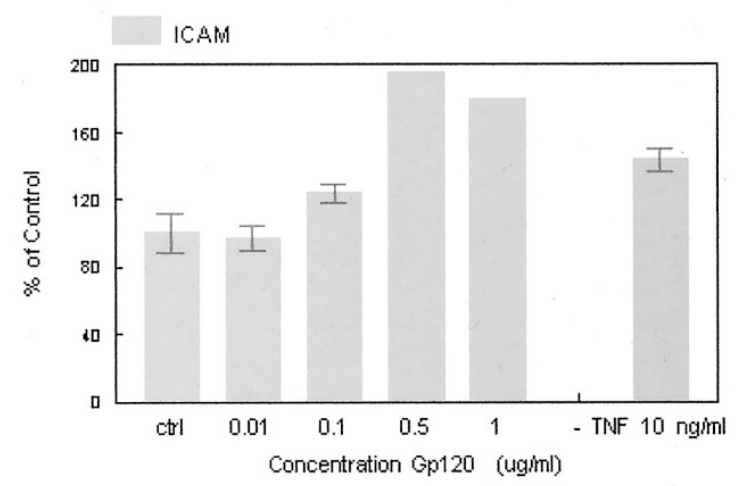

B

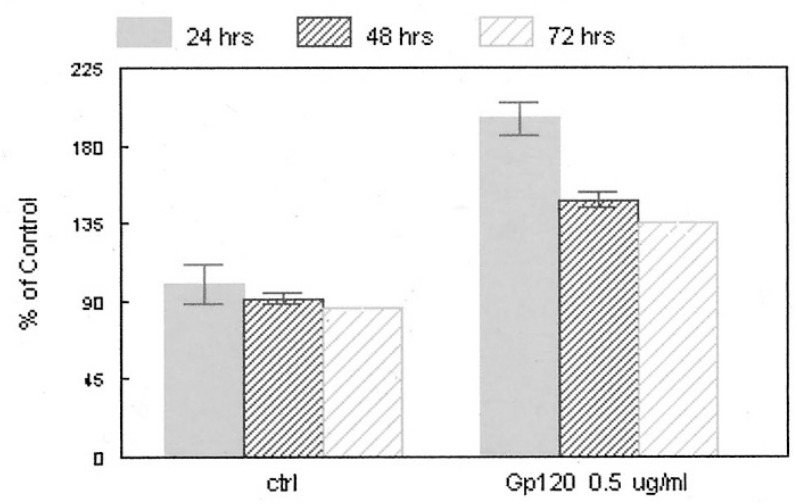

Figure 1.

Gp120-induced ICAM-1 expression on human brain microvascular endothelial cells (HBMEC): concentration and time dependence. (A) HBMEC were incubated with X4 gp120 $(0.01-1 \mu \mathrm{g} / \mathrm{ml})$ for 24 hours. As a positive control, HBMEC were stimulated with tumor necrosis factor (TNF)- $\alpha$ (10 ng/ml) for $24 \mathrm{hours}$. (B) HBMEC were incubated with X4 Gp120 (0.5 $\mu \mathrm{g} / \mathrm{ml})$ for 24,48 , and 72 hours. ICAM expression is indicated as percent of control (nonstimulated HBMEC).

A

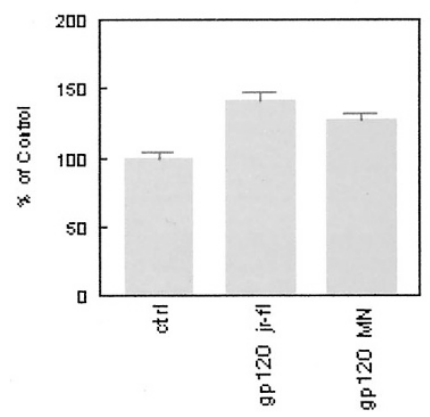

B

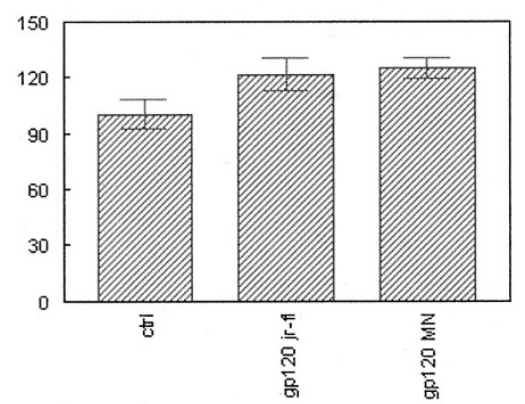

C

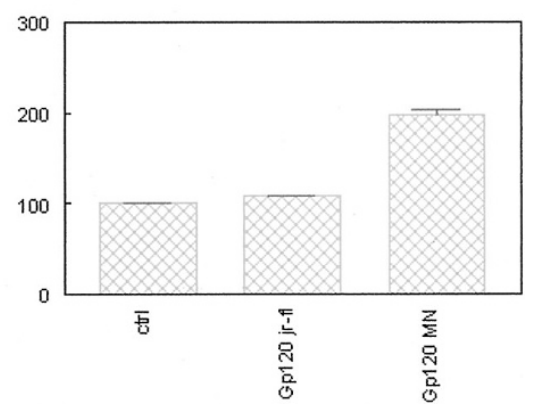

Figure 2.

ICAM-1 expression on HBMEC: R5 versus X4 gp120 on HBMEC derived from three different donors. Gp120 (0.1 $\mu \mathrm{g} / \mathrm{ml})$ was derived from R5 HIV-1 (JR-FL) or X4 HIV-1 (MN). ICAM-1 expression was expressed as percentage of control (nonstimulated HBMEC).

\section{Real-Time qPCR Analysis for ICAM-1 in HBMECs}

To determine whether the changes in ICAM-1 occurred at the transcriptional level, we performed realtime quantitative PCR analysis for ICAM-1. Three hours after addition of gp120-MN $(0.5 \mu \mathrm{g} / \mathrm{ml})$, the level of ICAM-1 mRNA expression doubled compared with the nontreated control (Fig. 3). Gp120 treatment persistently up-regulates the expression of ICAM-1 up until at least 6 hours, whereas it is reduced in the untreated sample (not shown). This indicates that gp120 up-regulates ICAM-1 expression by causing an increase at the level of mRNA expression.

\section{Chemokine Receptor Involvement in gp120-Mediated Increase in ICAM-1 Expression}

We showed that X4 and R5 gp120 increased ICAM-1 expression on pediatric HBMEC, but some disparities exist in responses to gp120 of different origin and among different HBMEC isolates. We did find that CD4 and chemokine receptor expressions vary among different HBMEC isolates (Stins et al, unpublished

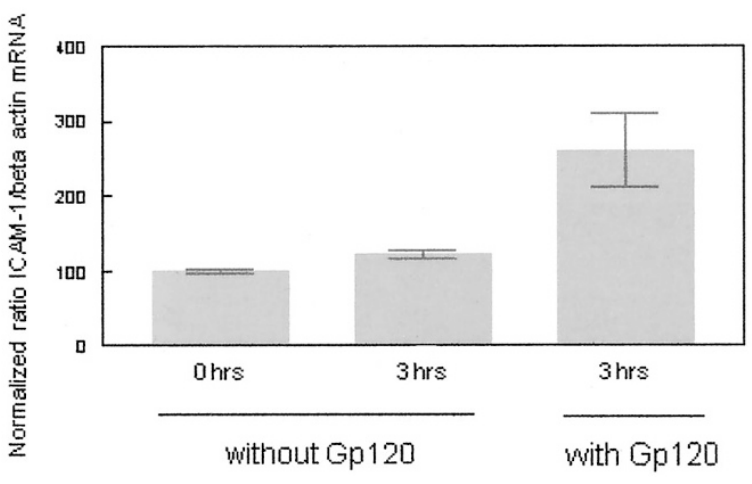

Figure 3.

Real-time quantitative polymerase chain reaction (PCR) analysis of ICAM-1 expression in HBMECs. Gp120-MN $(0.5 \mu \mathrm{g} / \mathrm{ml})$ was added to HBMEC and at 0,3 , and 6 hours. Real-time quantitative PCR was performed as indicated in Material and Methods. Data are expressed as ratio of ICAM- 1 to beta actin mRNA.

data), which could explain some of these disparities. We examined the involvement of CD4/chemokine coreceptors in the gp120-mediated increase in ICAM-1 
expression by using nonactivating antibodies directed against CD4 and chemokine coreceptors CCR3 and CCR5.

Because all anti-CXCR4 Mab were activating antibodies and elicited an ICAM-1 up-regulation, we used the small-molecule inhibitors of CXCR4: T140, TN140, and TC140 to assess the contribution of CXCR4 in X4 gp120 mediated up-regulation of ICAM-1.

Figure 4A shows that Mab against CCR3 and CCR5 and the small-molecule inhibitors against CXCR4 and TN140 alone cannot inhibit X4 gp120-mediated increases in ICAM-1 expression. However, when used in combination, anti-CCR3 and anti-CCR5, anti-CCR5 and TN140, but not anti-CCR3 and TN140, could inhibit X4 gp120-induced ICAM-1 expression. Figure 4B shows that the R5 gp120-mediated response can be inhibited with antibodies against chemokine coreceptors CCR3 and CCR5. As a control, smallmolecule CXCR4 inhibitor TN140 could not block R5 gp120-mediated ICAM-1 responses (not shown).

A

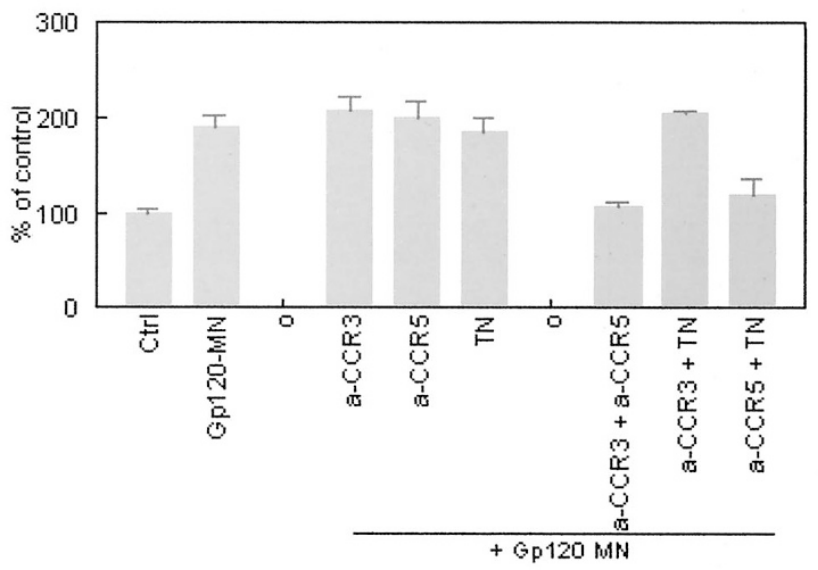

Thus, anti-CCR3 and anti-CCR5 antibodies, as expected, could not block activation of HBMEC by $\mathrm{X} 4$ gp120 but blocked the response to R5 gp120. Surprisingly, combinations of anti-CCR3/CCR5 and antiCCR5/TN140 but not CCR3/TN140 could inhibit X4 gp120 activation of HBMEC, suggesting that blockade of two receptors such as CCR3/CCR5 and CCR5/ CXCR4 inhibits X4 gp120-mediated activation of HBMEC. It is, however, unclear why such an inhibition was not observed with the combination of CCR3/CXCR4.

The contribution of CD4 was further investigated by using soluble CD4 and a nonactivating anti-CD4 Mab. Premixing of soluble CD4 with gp120 before their addition to HBMEC prevented ICAM-1 expression in response to X4 and R5 gp120 (Fig. 4C). Similarly, the addition of anti-CD4 Mab to HBMEC before gp120 decreased ICAM-1 expression induced by X4 and R5 gp120. These findings illustrate the important contri-

\section{C}
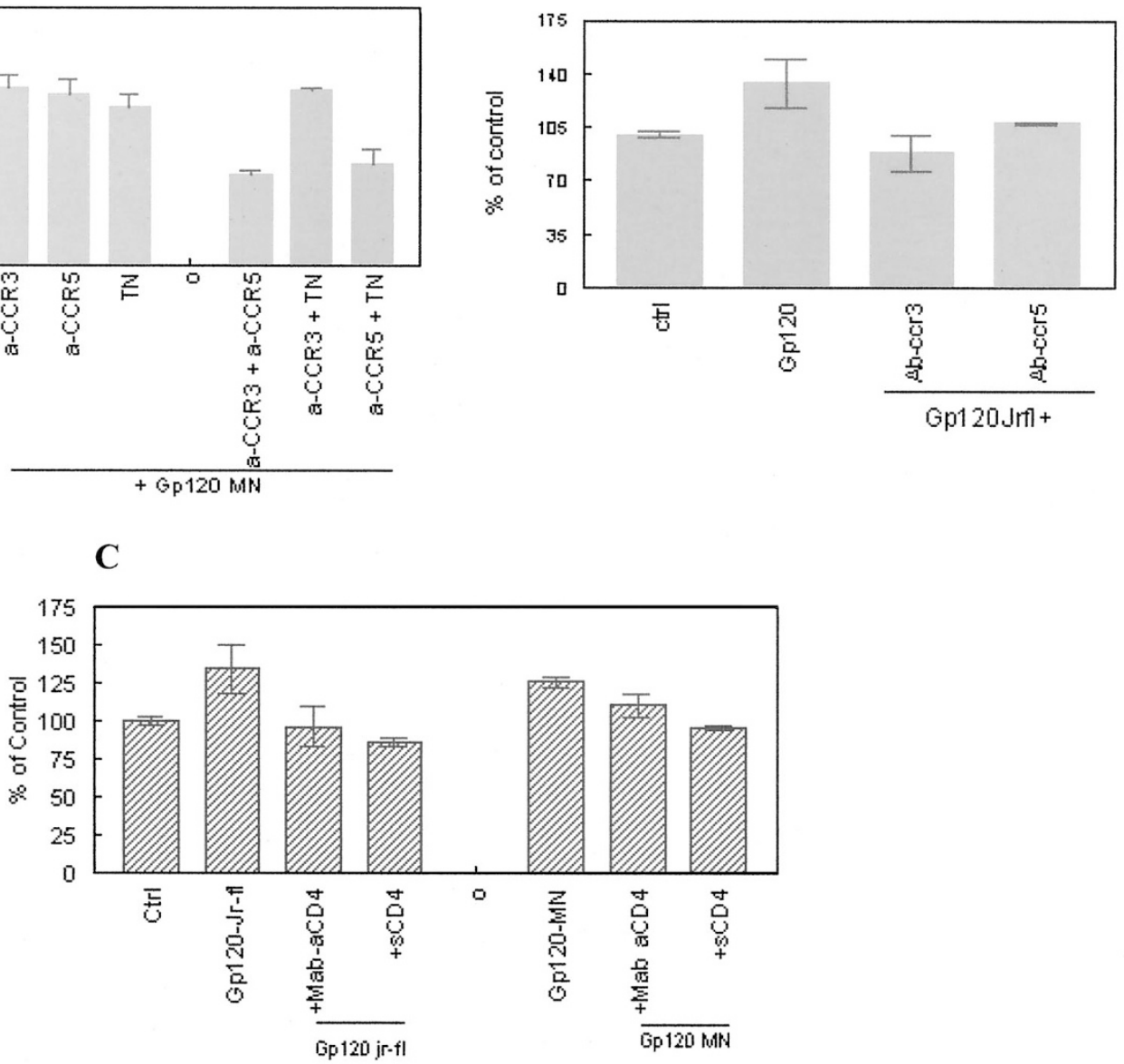

Figure 4.

Role of chemokine receptors and CD4 in gp120-induced ICAM-1 expression. A, Gp120-MN-induced ICAM-1 expression HBMEC were exposed to gp120 (0.1 $\mu$ g/ml) derived from X4 HIV-1 in the absence or presence of "inhibiting" antichemokine coreceptor antibodies (aCCR3 Mab RD155, aCCR5 Mab 5C7) or small molecule CXCR4 antagonist TN and the ICAM-1 expression on HBMEC determined by enzyme-linked immunoadsorbent assay (ELISA). B, Gp120-JR-FL induced ICAM-1 expression HBMEC were exposed to gp120 $(0.5 \mu \mathrm{g} / \mathrm{ml})$ derived from R5 HIV-1 in the absence or presence of "inhibiting" antichemokine coreceptor antibodies (aCCR3 Mab RD155, aCCR5 Mab 5C7). Subsequently, ICAM-1 expression on HBMEC was determined by ELISA. C, Role of CD4 in gp120-mediated increase in ICAM-1 expression. HBMEC were incubated with gp120 $(0.1 \mu \mathrm{g} / \mathrm{ml})$ in the absence or presence of inhibiting anti-CD4 antibodies (SIM4, DAKO) or soluble CD4, and ICAM-1 expression was determined. Shown are results obtained with X4 gp120 and R5 gp120. 
bution of CD4 to gp120-mediated activation on HBMEC.

By using "nonactivating" anti- $\beta$-chemokine coreceptor antibodies and small-molecule CXCR4 inhibitors, the roles of chemokine coreceptors in gp120mediated activation of HBMEC were found to differ between R5 and X4 gp120. For example, antibodies to $\beta$-chemokine coreceptors (CCR3, CCR5) alone inhibited R5 gp120 response. In contrast, the smallmolecule CXCR4 inhibitor could not inhibit T-tropic gp120-mediated ICAM-1 expression. However, an unexpected finding was the involvement of $\beta$-chemokine receptors (anti-CCR3, CCR5 antibodies) in the inhibition of X4 gp120-mediated increase of ICAM-1 expression of HBMEC.

\section{Signaling Pathways Involved in Gp120-Mediated ICAM-1 Expression}

ICAM-1 signaling pathways have been shown to involve NF-kB (Collins et al, 1995). We showed that R5 and X4 Gp120 induced translocation of NF-kB by gelshift assay (Fig. 5A). Addition of an inhibitor of NF-kB (Bay 117082) prevented X4 gp120-mediated increase in ICAM-1 expression (Fig. 5B). Chemokine coreceptors are shown to be G-protein-coupled re- ceptors (Feng et al, 1996). Next, we used ptx, an inhibitor of Gi/o-protein coupled receptors. Preincubation of HBMEC with ptx ( $100 \mathrm{ng} / \mathrm{ml})$ for 1 to 24 hours before addition of gp120 partially prevented the increase in ICAM-1 expression by X4 gp120 (from 177\% to $132 \%$ of the control) (Fig. 5 C). Similar results were found for R5 gp120. These findings indicate that G-protein-coupled receptors, such as chemokine coreceptors, are involved in R5 and X4 gp120-mediated ICAM-1 increase, but additional non- $\mathrm{G}_{\mathrm{i} / \mathrm{o}}$-protein coupled receptors may be involved.

\section{Discussion}

HIV-1-associated CNS disorders are severe complications of HIV-1 infection. It is generally assumed that HIV-1 enters the CNS by way of HIV-1-infected monocytes in an early stage of the disease. Monocytes and macrophages do not show a great propensity to transmigrate across the brain endothelial barrier unless a stimulus that attracts macrophages is present or the endothelium is activated. HIV-1 infection of macrophages by itself does not lead to an increased transmigration (Persidsky et al, 1997). Therefore, activation of brain endothelium must play an important
A

FP Ct GpJrfl GpMN

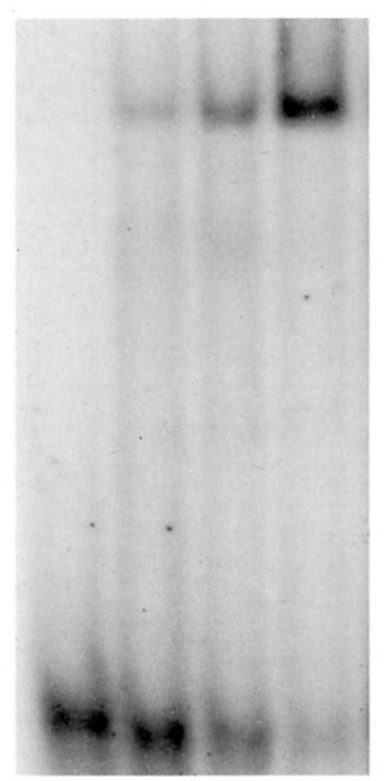

\section{B}

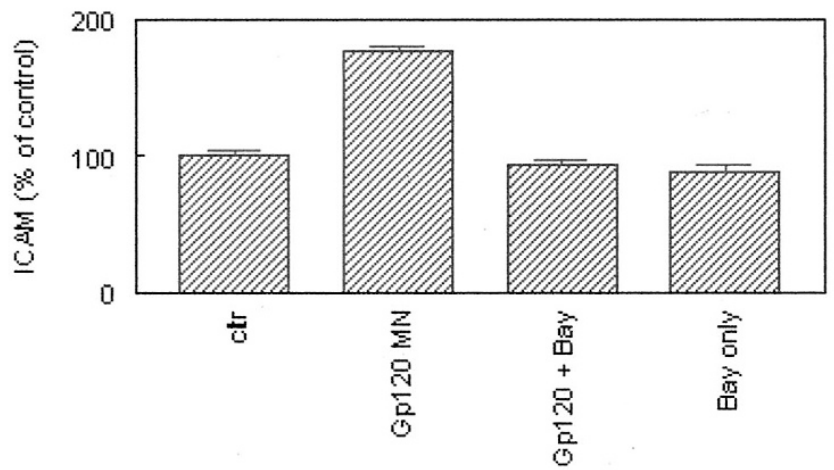

C

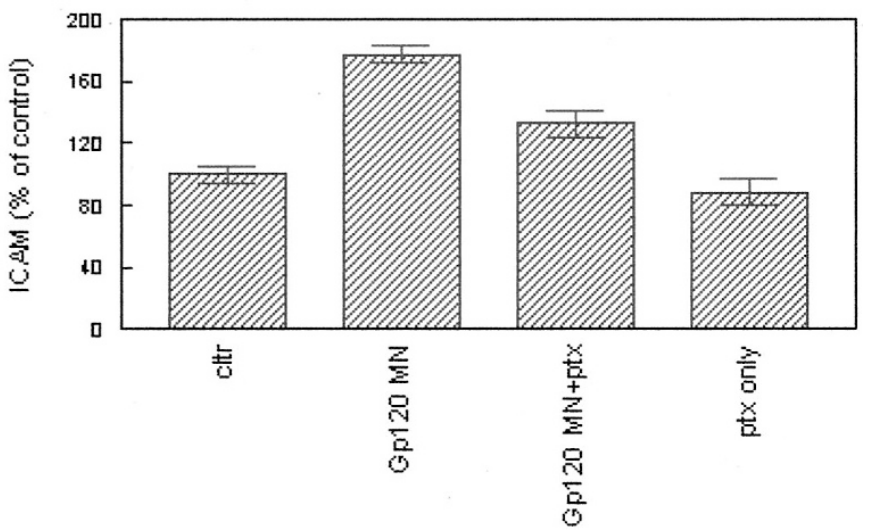

Figure 5.

Signaling pathways involved in gp120-induced ICAM-1 expression on HBMEC. HBMEC were preincubated with the indicated inhibitor for 1 hour with Bay (10 $\mu$ M) or pertussis toxin (ptx) $(100 \mathrm{ng} / \mathrm{ml})$ before addition of R5 or X4 gp120 (0.1 $\mathrm{g} / \mathrm{ml}$ MN or JRFL). A, Electrophoretic mobility shift for nuclear factor (NF)-kB indicates translocation induced by gp120 (FP, free probe; Ct, control). B, NF-kB inhibitor Bay 11-7082 inhibits gp120-induced ICAM-1 expression, indicating involvement of NF-kB signaling pathway. C, ptx inhibits gp120-induced ICAM-1 expression in HBMEC, indicating involvement of G-protein receptors. 
role in transmigration of monocytes. Factors that may activate brain endothelium in HIV-1 infection include cytokines, chemokines, and HIV-1 proteins (eg, gp120 shed by HIV-1 and HIV-1-infected cells). We have previously shown that gp120 can activate human brain endothelium derived from children in increasing ICAM1/VCAM-1 expression and monocyte transmigration (Stins et al, 2001). ICAM-1 expression in response to gp120 was later reported for other endothelial cell types derived from the skin (dermal), lungs, and coronary artery but not for VCAM-1 (Ren et al, 2002). In accordance with our findings, these authors found that human umbilical vein endothelial cells did not respond to gp120. Gp120-mediated induction of ICAM-1 has also been demonstrated in glial cells and astrocytes (Seilhean et al, 1997; Shrikant et al, 1996). Because the underlying mechanisms responsible for ICAM-1 induction by gp120 were unclear, we set out to study them in our HBMECs.

In the present study, we found that gp120 increased expression of ICAM-1 in a time- and dose-dependent manner. A maximal increase in ICAM-1 expression was found after 24 hours, which parallels the findings of cytokine-induced increase in ICAM-1 expression (Wong and Dorovini-Zis, 1992). Gp120-induced expression of ICAM-1 was not caused by contaminating endotoxin in the gp120 preparation because polymyxin B did not inhibit the response. Moreover, antibodies against gp120 blocked gp120-induced responses in ICAM-1 expression (not shown), which is consistent with the results of Ren et al (2002) and our previous findings on gp120-induced monocyte migration (Stins et al, 2001). The gp120-mediated increases in ICAM-1 expression are mediated at the mRNA level, which is in accordance with the findings of Ren et al (2002). Gp120 derived from X4 HIV-1 showed a consistent up-regulation of ICAM-1 expression, whereas the response to gp120 derived from R5 HIV-1 varied among HBMEC derived from different children. These differences could be caused by differences in the gp120-receptor(s) profile on HBMEC or the presence of the mutant CCR5-delta-32 receptor.

It is well known that gp120 uses CD4 or the chemokine coreceptors CCR3, CCR5, and CXCR4 (Choe et al, 1996; Deng et al, 1996; Doranz et al, 1997a; Dragic et al, 1996), but it is unclear how gp120 uses these receptors in up-regulation of ICAM-1 on HBMEC. Endothelium from the brain has been shown to display a differential panel of receptors for HIV-1 gp120, such as CD4 (Stins et al, 2001) and chemokine coreceptors CCR3, CCR5, and CXCR4 (Andjelkovic and Pachter, 2000; Berger et al, 1987; Edinger et al, 1997; Lavi et al, 1997; Mukhtar et al, 2002). A heterogeneity in receptor profile or the presence of mutant receptors in brain endothelial cells of different patients and regions may explain differences in responses to gp120 among HBMEC isolates derived from different patients. Our preliminary investigations revealed that receptor profiles differed among HBMEC derived from different patients, and some HBMEC were heterozygous for the delta 32-CCR5 receptor (not shown), which could explain the different responses to $\mathrm{R} 5$ versus X4 gp120.

We examined the involvement of CD4 or chemokine coreceptors in the gp120-mediated ICAM-1 expression by using several anti-CD4, CCR3, CCR5, and CXCR4 antibodies. Chemokine coreceptors are G-protein-coupled seven-transmembrane receptors (Bleul et al, 1996; Feng et al, 1996; Oberlin et al, 1996), and antibodies raised against these coreceptors are commercially available. To demonstrate the (co-) receptor involvement in gp120-mediated ICAM expression, we used nonactivating anti-CCR3 and CCR5 antibodies and small-molecule inhibitors (TN) for CXCR4. This approach demonstrated that X4 gp120 response could not be inhibited by anti-CCR3 and CCR5 antibodies or TN alone, but, surprisingly, a combination of anti-CCR3 and CCR5 antibodies or anti-CCR5 antibody and TN abrogated the response. As expected, both anti-CCR3 and CCR5 antibodies inhibited the increase in ICAM-1 expression in response to R5 gp120. Soluble CD4 and antibodies to CD4 inhibited ICAM-1 expression in response to R5 and X5 gp120. These findings indicate that, for R5 gp120, the individual chemokine receptors CCR3 and CCR5 or CD4 could be sufficient to elicit a response in HBMEC. For X4 gp120, soluble CD4 completely inhibited the ICAM-1 increase, whereas antibodies against CD4 were only partially inhibitory. The responses of HBMEC to X4 gp120 seem to be more complicated than those to R5 gp120 and were regulated by a collaboration of two chemokine receptors of CCR3 and CCR5 or CCR5 and CXCR4. In contrast, the combination of CCR3 and CXCR4 failed to inhibit X4 gp120-mediated ICAM-1 expression, and the reasons for this discrepancy between CCR5/CXCR4 and CCR3/CXCR4 are not clear. Of interest, X4 gp120mediated tissue factor production in smooth muscle cells was also shown to be dependent on two coreceptors, CCR5 and CXCR4, and also dependent on the presence of functional CD4 (Schecter et al, 2001). As far as the involvement of chemokine receptors, gp120 induced other cellular responses; for human umbilical vein endothelial cells, mainly CXCR4 but also CCR5 were shown to be involved in apoptosis induction by X4 gp120 (Huang et al, 2001; Ullrich et al, 2000), and, in neuroblastoma cells, cell death involved both CXCR4 and CCR5 (Catani et al, 2000). The involvement of both alpha and beta chemokine coreceptors (CXCR4 and CCR3/CCR5, respectively) in a X4 gp120 response appears unusual, and this may be because of possible promiscuity of gp120 for different coreceptors.

The degree whereby gp120 can activate human cells may not only be dependent on the viral origin but also on the expression level or efficiency of the interaction of the coreceptors with CD4 or the gp120-CD4 complex (Dimitrov et al, 1999; Mondor et al, 1998). It has been shown that this interaction may differ for different cells types (eg, CD4-CXCR4 interaction is more efficient in lymphocytes and monocytes than in macrophages) (Dimitrov et al, 1999). Efficiency of gp120 binding and subsequent signaling by corecep- 
tors may depend on receptor mutations and differences in posttranslational modifications (eg, glycosylations, sulfations). In addition, gp120 viral origin may display differences in binding to one or more regions of the receptor. For example, CXCR4 displays a considerable heterogeneity, SDF-1 can bind to the $\mathrm{N}$-terminal of CXCR4 without conferring signaling, and binding to the second extracellular loop triggers signaling, whereas mutations in the third extracellular loop affects transduction of G-protein signaling (Baribaud et al, 2001; Brelot et al, 2000; Lu et al, 1997; Wang et al, 1998). For CCR5 specifically, posttranslational sulfations were shown to be of importance for CCR5 binding to gp120-CD4 complexes (Farzan et al, 1999). In addition, other factors exist that may affect presentation or the availability of receptors on the membranes, such as membrane composition (cholesterol-lipid or sphingoglycolipids raft formation), and heparan sulfate proteoglycans may modulate the responsiveness of CXCR4, CCR3, CCR5, or CD4 to gp120 (Fantini et al, 2000; Liao et al, 2001; Mbemba et al, 1999; Mondor et al, 1998; Patel et al, 1993). Taken together, subtle differences in gp120 binding affinities, or gp120/CD4 complexes to chemokine coreceptors of different HBMEC, which may possess different mutations or posttranslational modifications in a variable membrane environment, may lead to the observed discrepancies in ICAM-1 responses of HBMEC derived from different patients.

ICAM-1 is a cytokine-inducible cell adhesion molecule, the physiologic ligand for leukocyte function associated antigen-1 and membrane attack complex-1, and is involved in extravasation of leukocytes (for review, see van de and van der Sag, 1996). Migration of HIV-1-infected monocytes across the BBB seems to be a major pathway for HIV-1 entry into the CNS. Thus, up-regulation of ICAM-1 expression on the brain endothelium could lead to increased adhesion and transmigration of (HIV-1-infected) monocytes/macrophages, thereby perpetuating HIV-1 pathogenesis. We have previously shown, using our in vitro model of the human BBB, that gp120 can enhance transmigration of monocytic cells (Stins et al, 2001). In vivo, it was shown that ICAM-1/NCAM-1 are significantly up-regulated in the brain of AIDS patients (Seilhean et al, 1997), and endothelium of gp120transgenic mice show a significant up-regulation of ICAM-1 expression (Toneatto et al, 1999). ICAM-1 present on endothelium can be cleaved of the membrane and subsequently released into the serum or cerebrospinal fluid. Levels of soluble ICAM-1 are indeed found to be increased in plasma and cerebral spinal fluid of pediatric and adult AIDS patients (Gaddi et al, 2000; Most et al, 1993; Rieckmann et al, 1993) and have been indicated as a marker for disease progression. Moreover, it was shown that ICAM-1/ LFA-1 may play a role in HIV-1-dependent cell fusion, cytopathicity (Hildreth and Orentas, 1989), and endothelial infection by HIV-1 (Scheglovitova et al, 1995). Therefore, it is of importance to study the mechanisms whereby HIV-1 proteins up-regulate ICAM-1 expression on the endothelium of the BBB. This may lead to development of specific inhibitors of either adhesion and extravasation of HIV-1-infected monocytes into the brain or of the inhibition of ICAM-1-dependent HIV-1 infection or endothelial activation.

In summary, in this article, we showed that gp120 increases ICAM-1 expression by way of its interaction with CD4 and chemokine coreceptors. Chemokine receptors are G-protein-coupled seven-transmembrane receptors (Bleul et al, 1996; Feng et al, 1996; Oberlin et al, 1996) and sensitive to ptx (Davis et al, 1997). We confirmed the involvement of the ptx-sensitive coreceptor pathway in gp120-mediated increase in ICAM-1 expression in our HBMEC. It is also known that the promotor for ICAM-1 expression contains NF-kB, which is involved in cytokine up-regulation of ICAM-1 (Collins et al, 1995), and, as shown here, the translocation of NF-kB by gelshift assay and the use of NF-kB inhibitor Bay indicated that gp120 uses the NF-kB signaling pathways in a manner analogous to the cytokinemediated pathways. Gp120 can signal through other pathways (eg, signal transducer and activator of transcription- $1 \alpha$ and Janus kinase) (Shrikant et al, 1996) or indirectly by way of TNF- $\alpha$, IFN- $\gamma$, or IL-10 (Capobianchi, 1996). However, we were not able to find a gp120-mediated increase in TNF- $\alpha$, IFN- $\gamma$, or IL-10 secretion by gp120 in HBMEC (not shown), and it is therefore unlikely that these "indirect" mechanisms are involved in the gp120-mediated increase in ICAM-1 expression in HBMEC. It appears that gp120 signaling pathways resulting in different phenotypes are likely to differ between HBMEC and other cell types such as T cells, neurons, and glial cells and that gp120 has a choice of triggering alternate signaling pathways in various cell types, including HBMEC.

\section{Materials and Methods}

\section{Isolation and Culture of Human Brain Microvessel Endothelial Cells}

Human brain microvessels were isolated from children's brain specimens derived from surgeries for seizure disorders and cultured as described previously (Stins et al, 1997). Human brain microvessels were plated on rat tail collagen and cultured in RPMI 1640 based medium with 10\% fetal bovine serum, $10 \%$ NuSerum, endothelial cell growth supplement (30 $\mu \mathrm{g} / \mathrm{ml})$ (Collaborative Biomedical Products, B\&D, Bedford, Massachusetts), heparin (5 U/ml), L-glutamine (2 mm), sodium pyruvate (1 mm), minimal essential medium vitamins, minimal essential medium nonessential amino acids, penicillin, and streptomycin (100 U/ml) (Irvine Scientific, Irvine, California). Endothelial cell cultures were incubated at $37^{\circ} \mathrm{C}$ in a humid atmosphere of $5 \% \mathrm{CO}_{2}$ and characterized for the presence of Factor VIII-Rag and AcLDL uptake. HBMEC with a purity greater than $99 \%$ endothelial cell population were obtained by FACS as previously described (Stins et al, 1997) and used in our experiments. 


\section{Antibodies and Inhibitors Used}

Antibodies against chemokine coreceptors CD4 and soluble CD4 were obtained from the AIDS Research and Reagent Program, Division of AIDS, NIAID, NIH, (Bethesda, Maryland) as follows: antibodies against CCR3, \#MAB155, from R\&D systems (Minneapolis, Minnesota); CCR5 antibodies 12D1 from Dr. Stephen Peiper (Doranz et al, 1997b), and 5C7 from LeukoSite, Incorporated (Cambridge, Massachusetts) (Wu et al, 1997). CD4 antibodies were obtained as follows: MAb SIM2 from Dr. James Hildreth (McCallus et al, 1992) and soluble CD4 from Dr. Sweet, (GlaxoSmithKline, Welwyn Garden City, Hertfordshire, UK) (Deen et al, 1988). Anti-gp120 antibodies (No 902, F105, and AD3) were from Dr. B Cheseboro, Dr. M. Posner (Posner et al, 1993) Dr. K. Ugen, and Dr. D. Weiner (Ugen, 1993). Antibody against CD4 (clone MT310) was purchased from DAKO (Carpinteria, California). Small-molecule chemokine coreceptor inhibitor T140, TN, or TC were kindly donated by Dr. Fujii of Kyoto University, Japan (Tamamura et al, 2001).

\section{Activation of HBMEC with gp120}

HBMEC derived from different patients were seeded in 96-well plates, grown to confluence, and subsequently treated with gp120 (0.1 up to $1 \mu \mathrm{g} / \mathrm{ml})$ in RPMI with $5 \%$ fetal bovine serum for 6,24 , or 72 hours. Gp120 from X4 HIV-1 (MN-CM) and from R5 HIV-1 (JR-FL) were obtained through the Reference Reagent Program, Division of AIDS, NIAID, NIH, and supplied by the following companies: MicroGeneSys (Meriden, Connecticut), Immunodiagnostics (Bedford, Massachusetts), and Progenics Pharmaceuticals (Tarrytown, New York) (McCutchan et al, 1992),

Expression of ICAM-1 was assessed by ELISA using anti-ICAM-1 antibodies from Immunotech/ Coulter (Westbrook, Maine) or biotinylated antiICAM-1 antibody from Chemicon (Temecula, California) using the $A B C$-alkaline phosphatase method as described previously (Stins et al, 1997). The results were expressed as percentage of untreated control cells.

For inhibition experiments, Bay 11-7082 (NF-kB inhibitor) or ptx (Gi/o-coupled protein inhibitor) (Sigma, St Louis, Missouri), antichemokine receptor antibodies, soluble CD4, or small-molecule chemokine coreceptor inhibitors ( $T, T N)$ were included in the medium during exposure of HBMEC to gp120. The effects of the indicated reagents on the gp120 mediated ICAM-1 expression on HBMEC were assessed.

Viability of the HBMEC were monitored by visual inspection using a microscope, live-dead stain (Molecular Probes, Eugene, Oregon), and by lactate dehydrogenase release in the supernatant using cytotoxicity detection kit (Roche, Mannheim, Germany). After 24 hours at $37^{\circ} \mathrm{C}$ treatment with gp120 (up to $1 \mu \mathrm{g} / \mathrm{ml}$ ), we did not find any evidence of cell death by any of the above methods (not shown).

\section{Real-Time Quantitative PCR Analysis of ICAM-1 Expression in HBMECs}

HBMEC where grown to confluence on collagencoated 24-wells plates and treated with gp120 (0.5 $\mu \mathrm{g} / \mathrm{ml}$ ) for up to 24 hours as previously indicated. Samples for RNA extraction were collected at time 0 , 3 hours, and 6 hours. Total RNA was extracted using RNeasy Mini Kit (Qiagen, Valencia, California). The amount and the quality of the RNA was verified by measuring the absorbance at 260 and $280 \mathrm{~nm}$.

Oligo (dT) primed Reverse Transcription of RNA was performed using SuperScript First-Strand Synthesis System for RT-PCR (Invitrogen, Carlsbad, California) using $50 \mathrm{ng}$ of RNA for each reaction; reactions without reverse transcriptase were concurrently prepared for each RNA sample to verify the absence of DNA contamination.

Real-time PCR analysis of ICAM- 1 expression was performed using specific primers $431 f$ (5'AGCCAGTGGGCAAGAACC) and 1036r (5'GGTCCCTTCTGAGACCTC), and $\beta$-actin amplification using commercial primers (QuantumRNA $\beta$-actin Internal Standards; Ambion, Austin, Texas) was used as reference.

Serial dilutions of cDNA were PCR amplified using a LightCycler System (Roche Applied Science, Indianapolis, Indiana) in 1x LightCycler-FastStart DNA Master SYBR Green I reaction mix with $3 \mathrm{~mm} \mathrm{Mg}^{2+}$. The PCR program consisted of one preincubation at $95^{\circ} \mathrm{C}$ for 10 minutes and 40 cycles at $95^{\circ} \mathrm{C}$ for 10 seconds, $55^{\circ} \mathrm{C}$ for 5 seconds and $72^{\circ} \mathrm{C}$ extension, followed by the melting curve analysis program described by the manufacturer; extension time was 20 seconds for ICAM-1 amplification and 12 seconds for $\beta$-actin amplification.

\section{Gelshift Assay}

HBMEC were seeded in $35 \mathrm{~mm}$ tissue culture dishes and stimulated with gp120 $(0.1-0.5 \mu \mathrm{g} / \mathrm{ml})$ for 30 minutes and 1 hour. Subsequently, nuclear extracts were prepared according to Schreiber et al (1989) with the modifications of Molitor (1990). The nuclear extracts were snap frozen and stored at $-80^{\circ} \mathrm{C}$. Probes for NF-kB were obtained from Santa Cruz Biochemicals (Santa Cruz, California) and labeled with 32P using DNA endlabeling kit (GIBCO-BRL, Gaithersburg, Maryland) according to the manufacturers instructions. ${ }^{32} \mathrm{P}$-labeled NF-kB probe was purified with a Stratagene (La Jolla, California) push column, incubated with the nuclear extracts, separated with PAGE, and the bands were subsequently visualized with autoradiography.

\section{Conclusion}

We showed that chemokine co-receptors and CD4 receptors are involved in the response of human brain endothelium to R5 and X4 gp120 by increasing ICAM-1 expression in ptx and NF-kB-dependent pathways. The degree of ICAM-1 up-regulation differs for R5 versus X4 gp120 and also among the various 
HBMEC isolates. Endothelial cells are important regulators of immune function and inflammatory reactions. Thus, endothelial activation may lead to compromised function of the BBB. Because ICAM-1 is an adhesion molecule shown to be involved in extravasation of monocytic cells, increased ICAM-1 expression may lead to increased influx of (HIV-1) infected monocytes into the CNS. This may explain our previous demonstration that gp120 increased transmigration of monocytes across the human BBB model. In addition, the presence of CD4 on the brain endothelium of children may explain an increased incidence of HIV-1 CNS involvement in pediatric AIDS patients.

\section{Acknowledgements}

The authors thank Henry A. Choy, UCLANAGLAHS, Los Angeles, California, for his advice on the gelshift assay for NF-kB.

\section{References}

Andjelkovic AV and Pachter JS (2000). Characterization of binding sites for chemokines MCP-1 and MIP-1alpha on human brain microvessels. J Neurochem 75:1898-1906.

Annunziata P, Cioni C, Toneatto S, and Paccagnini E (1998). HIV-1 gp120 increases the permeability of rat brain endothelium cultures by a mechanism involving substance P. AIDS 12:2377-2385.

Banks WA, Kastin AJ, and Akerstrom V (1997). HIV-1 protein gp120 crosses the blood-brain barrier: Role of adsorptive endocytosis. Life Sci 61:L119-L125.

Baribaud F, Edwards TG, Sharron M, Brelot A, Heveker N, Price K, Mortari F, Alizon M, Tsang M, and Doms RW (2001). Antigenically distinct conformations of CXCR4. J Virol 75: 8957-8967.

Berger JR, Moskowitz L, Fischl M, and Kelley RE (1987). Neurologic disease as the presenting manifestation of acquired immunodeficiency syndrome. South Med J 80:683686.

Berger JR, Nath A, Greenberg RN, Andersen AH, Greene RA, Bognar A, and Avison MJ (2000). Cerebrovascular changes in the basal ganglia with HIV dementia. Neurology 54:921-926.

Berger O, Gan X, Gujuluva C, Burns AR, Sulur G, Stins M, Way D, Witte M, Weinand M, Said J, Kim KS, Taub D, Graves MC, and Fiala M (1999). CXC and CC chemokine receptors on coronary and brain endothelia. Mol Med 5:795-805.

Bleul CC, Farzan M, Choe H, Parolin C, Clark-Lewis I, Sodroski J, and Springer TA (1996). The lymphocyte chemoattractant SDF-1 is a ligand for LESTR/fusin and blocks HIV-1 entry. Nature 382:829-833.

Brelot A, Heveker N, Montes M, and Alizon M (2000). Identification of residues of CXCR4 critical for human immunodeficiency virus coreceptor and chemokine receptor activities. J Biol Chem 275:23736-23744.

Buttner A, Mehraein P, and Weis S (1996). Vascular changes in the cerebral cortex in HIV-1 infection. II. An immunohistochemical and lectinhistochemical investigation. Acta Neuropathol (Berl) 92:35-41.
Capobianchi MR (1996). Induction of lymphomonocyte activation by HIV-1 glycoprotein gp120. Possible role in AIDS pathogenesis. J Biol Regul Homeost Agents 10:83-91.

Catani MV, Corasaniti MT, Navarra M, Nistico G, FinazziAgro A, and Melino G (2000). gp120 induces cell death in human neuroblastoma cells through the CXCR4 and CCR5 chemokine receptors. J Neurochem 74:2373-2379.

Choe H, Farzan M, Sun Y, Sullivan N, Rollins B, Ponath PD, Wu L, Mackay CR, LaRosa G, Newman W, Gerard N, Gerard C, and Sodroski J (1996). The beta-chemokine receptors CCR3 and CCR5 facilitate infection by primary HIV-1 isolates. Cell 85:1135-1148.

Collins T, Read MA, Neish AS, Whitley MZ, Thanos D, and Maniatis T (1995). Transcriptional regulation of endothelial cell adhesion molecules: NF-kappa B and cytokine-inducible enhancers. FASEB J 9:899-909.

Craig LE, Spelman JP, Strandberg JD, and Zink MC (1998). Endothelial cells from diverse tissues exhibit differences in growth and morphology. Microvasc Res 55:65-76.

Da Cunha A, Jackson RW, and Vitkovic L (1995). HIV-1 non-specifically stimulates production of transforming growth factor-beta 1 transfer in primary astrocytes. J Neuroimmunol 60:125-133.

Davis CB, Dikic I, Unutmaz D, Hill CM, Arthos J, Siani MA, Thompson DA, Schlessinger J, and Littman DR (1997). Signal transduction due to HIV-1 envelope interactions with chemokine receptors CXCR4 or CCR5. J Exp Med 186:1793-1798.

Deen KC, McDougal JS, Inacker R, Folena-Wasserman G, Arthos J, Rosenberg J, Maddon PJ, Axel R, and Sweet RW (1988). A soluble form of CD4 (T4) protein inhibits AIDS virus infection. Nature 331:82-84.

Deng H, Liu R, Ellmeier W, Choe S, Unutmaz D, Burkhart M, Di Marzio P, Marmon S, Sutton RE, Hill CM, Davis CB, Peiper SC, Schall TJ, Littman DR, and Landau NR (1996). Identification of a major co-receptor for primary isolates of HIV-1 [see comments]. Nature 381:661-666.

Dimitrov DS, Norwood D, Stantchev TS, Feng Y, Xiao X, and Broder CC (1999). A mechanism of resistance to HIV-1 entry: inefficient interactions of CXCR4 with CD4 and gp120 in macrophages. Virology 259:1-6.

Doranz BJ, Berson JF, Rucker J, and Doms RW (1997a). Chemokine receptors as fusion cofactors for human immunodeficiency virus type 1 (HIV-1). Immunol Res 16:15-28.

Doranz BJ, Lu ZH, Rucker J, Zhang TY, Sharron M, Cen YH, Wang ZX, Guo HH, Du JG, Accavitti MA, Doms RW, and Peiper SC (1997b). Two distinct CCR5 domains can mediate coreceptor usage by human immunodeficiency virus type 1 . J Virol 71:6305-6314.

Dragic T, Litwin V, Allaway GP, Martin SR, Huang Y, Nagashima KA, Cayanan C, Maddon PJ, Koup RA, Moore JP, and Paxton WA (1996). HIV-1 entry into CD4+ cells is mediated by the chemokine receptor CC- CKR-5 [see comments]. Nature 381:667-673.

Edinger AL, Mankowski JL, Doranz BJ, Margulies BJ, Lee B, Rucker J, Sharron M, Hoffman TL, Berson JF, Zink MC, Hirsch VM, Clements JE, and Doms RW (1997). CD4independent, CCR5-dependent infection of brain capillary endothelial cells by a neurovirulent simian immunodeficiency virus strain. Proc Natl Acad Sci USA 94:14742-14747. 
Fantini J, Hammache D, Pieroni G, and Yahi N (2000). Role of glycosphingolipid microdomains in CD4-dependent HIV-1 fusion. Glycoconj J 17:199-204.

Farzan M, Mirzabekov T, Kolchinsky P, Wyatt R, Cayabyab M, Gerard NP, Gerard C, Sodroski J, and Choe H (1999). Tyrosine sulfation of the amino terminus of CCR5 facilitates HIV-1 entry. Cell 96:667-676.

Feng Y, Broder CC, Kennedy PE, and Berger EA (1996). HIV-1 entry cofactor: Functional cDNA cloning of a seventransmembrane, G protein-coupled receptor [see comments]. Science 272:872-877.

Fiala M, Looney DJ, Stins M, Way DD, Zhang L, Gan X, Chiappelli F, Schweitzer ES, Shapshak P, Weinand $M$, Graves MC, Witte M, and Kim KS (1997). TNF-alpha opens a paracellular route for HIV-1 invasion across the blood-brain barrier. Mol Med 3:553-564.

Finkel TH, Tudor-Williams G, Banda NK, Cotton MF, Curiel T, Monks C, Baba TW, Ruprecht RM, and Kupfer A (1995). Apoptosis occurs predominantly in bystander cells and not in productively infected cells of HIV- and SIV-infected lymph nodes [see comments]. Nat Med 1:129-134.

Gaddi E, Laucella S, Balbaryski J, Cantisano C, Barboni G, Candi M, and Giraudi V (2000). Prognostic value of soluble intercellular adhesion molecule-1 (s-ICAM-1) in HIV-infected children. Scand J Immunol 52:628-633.

Hesselgesser J, Taub D, Baskar P, Greenberg M, Hoxie J, Kolson DL, and Horuk R (1998). Neuronal apoptosis induced by HIV-1 gp120 and the chemokine SDF-1 alpha is mediated by the chemokine receptor CXCR4. Curr Biol 8:595-598.

Hildreth JE and Orentas RJ (1989). Involvement of a leukocyte adhesion receptor (LFA-1) in HIV-induced syncytium formation. Science 244:1075-1078.

Huang MB, Khan M, Garcia-Barrio M, Powell M, and Bond VC (2001). Apoptotic effects in primary human umbilical vein endothelial cell cultures caused by exposure to virionassociated and cell membrane-associated HIV-1 gp120. J Acquir Immune Defic Syndr 27:213-221.

Ilyin SE and Plata-Salaman CR (1997). HIV-1 envelope glycoprotein 120 regulates brain IL-1beta system and TNFalpha mRNAs in vivo. Brain Res Bull 44:67-73.

Kumar S, West DC, and Ager A (1987). Heterogeneity in endothelial cells from large vessels and microvessels. Differentiation 36:57-70.

Lafeuillade A, Alessi MC, Poizot-Martin I, Boyer-Neumann C, Zandotti C, Quilichini R, Aubert L, Tamalet C, Juhan-Vague I, and Gastaut JA (1992). Endothelial cell dysfunction in HIV infection. J Acquir Immune Defic Syndr 5:127-131.

Lannuzel A, Barnier JV, Hery C, Huynh VT, Guibert B, Gray F, Vincent JD, and Tardieu M (1997). Human immunodeficiency virus type 1 and its coat protein gp120 induce apoptosis and activate JNK and ERK mitogen-activated protein kinases in human neurons. Ann Neurol 42:847-856.

Lavi E, Strizki JM, Ulrich AM, Zhang W, Fu L, Wang Q, O'Connor M, Hoxie JA, and Gonzalez-Scarano F (1997). CXCR-4 (Fusin), a co-receptor for the type 1 human immunodeficiency virus (HIV-1), is expressed in the human brain in a variety of cell types, including microglia and neurons. Am J Pathol 151:1035-1042.

Liao Z, Cimakasky LM, Hampton R, Nguyen DH, and Hildreth JE (2001). Lipid rafts and HIV pathogenesis: host membrane cholesterol is required for infection by HIV type 1. AIDS Res Hum Retroviruses 17:1009-1019.

Liu NQ, Lossinsky AS, Popik W, Li X, Gujuluva C, Kriederman B, Roberts J, Pushkarsky T, Bukrinsky M, Witte M, Weinand $M$, and Fiala $M$ (2002). Human immunodeficiency virus type 1 enters brain microvascular endothelia by micropinocytosis dependent on lipid rafts and the mitogen-activated protein kinase signaling pathway. J Virol 76:6689-6700.

Lu Z, Berson JF, Chen Y, Turner JD, Zhang T, Sharron M, Jenks MH, Wang Z, Kim J, Rucker J, Hoxie JA, Peiper SC, and Doms RW (1997). Evolution of HIV-1 coreceptor usage through interactions with distinct CCR5 and CXCR4 domains. Proc Natl Acad Sci U S A 94:6426-6431.

MacLean AG, Orandle MS, Alvarez X, Williams KC, and Lackner AA (2001). Rhesus macaque brain microvessel endothelial cells behave in a manner phenotypically distinct from umbilical vein endothelial cells. J Neuroimmunol 118: 223-232.

Mankowski JL, Queen SE, Kirstein LM, Spelman JP, Laterra J, Simpson IA, Adams RJ, Clements JE, and Zink MC (1999). Alterations in blood-brain barrier glucose transport in SIVinfected macaques. J Neurovirol 5:695-702.

Mbemba E, Benjouad A, Saffar L, and Gattegno L (1999). Glycans and proteoglycans are involved in the interactions of human immunodeficiency virus type 1 envelope glycoprotein and of SDF-1alpha with membrane ligands of CD4(+) CXCR4(+) cells. Virology 265:354-364.

McCallus DE, Ugen KE, Sato Al, Williams WV, and Weiner DB (1992). Construction of a recombinant bacterial human CD4 expression system producing a bioactive CD4 molecule. Viral Immunol 5:163-172.

McCutchan FE, Hegerich PA, Brennan TP, Phanuphak P, Singharaj P, Jugsudee A, Berman PW, Gray AM, Fowler AK, and Burke DS (1992). Genetic variants of HIV-1 in Thailand. AIDS Res Hum Retroviruses 8:1887-1895.

Molitor JA, Walker WH, Doerre S, Ballard DW, and Greene WC (1990). NF-kappa B: A family of inducible and differentially expressed enhancer-binding proteins in human $\mathrm{T}$ cells. Proc Natl Acad Sci U S A 87:10028-10032.

Mondor I, Ugolini S, and Sattentau QJ (1998). Human immunodeficiency virus type 1 attachment to HeLa CD4 cells is CD4 independent and gp120 dependent and requires cell surface heparans. J Virol 72:3623-3634.

Moses AV, Bloom FE, Pauza CD, and Nelson JA (1993). Human immunodeficiency virus infection of human brain capillary endothelial cells occurs via a CD4/ galactosylceramide-independent mechanism. Proc Natl Acad Sci USA 90:10474-10478.

Most J, Zangerle R, Herold M, Fuchs D, Wachter H, Fritsch P, and Dierich MP (1993). Elevated concentrations of circulating intercellular adhesion molecule 1 (ICAM-1) in HIV-1 infection. $\mathrm{J}$ Acquir Immune Defic Syndr 6:221-226.

Mukhtar M, Harley S, Chen P, BouHamdan M, Patel C, Acheampong E, and Pomerantz RJ (2002). Primary isolated human brain microvascular endothelial cells express diverse HIV/SIV-associated chemokine coreceptors and DC-SIGN and L-SIGN. Virology 297:78-88.

Nottet HS, Persidsky Y, Sasseville VG, Nukuna AN, Bock P, Zhai QH, Sharer LR, McComb RD, Swindells S, Soderland C, and Gendelman HE (1996). Mechanisms for the transendo- 
thelial migration of HIV-1-infected monocytes into brain. $\mathrm{J}$ Immunol 156:1284-1295.

Oberlin E, Amara A, Bachelerie F, Bessia C, Virelizier JL, Arenzana-Seisdedos F, Schwartz O, Heard JM, Clark-Lewis I, Legler DF, Loetscher M, Baggiolini M, and Moser B (1996). The CXC chemokine SDF-1 is the ligand for LESTR/fusin and prevents infection by T-cell-line-adapted HIV-1. Nature 382: 833-835.

Patel M, Yanagishita M, Roderiquez G, Bou-Habib DC, Oravecz T, Hascall VC, and Norcross MA (1993). Cell-surface heparan sulfate proteoglycan mediates HIV-1 infection of T-cell lines. AIDS Res Hum Retroviruses 9:167-174.

Persidsky Y, Stins M, Way D, Witte MH, Weinand M, Kim KS, Bock P, Gendelman HE, and Fiala M (1997). A model for monocyte migration through the blood-brain barrier during HIV-1 encephalitis. J Immunol 158:3499-3510.

Persidsky Y, Zheng J, Miller D, and Gendelman HE (2000). Mononuclear phagocytes mediate blood-brain barrier compromise and neuronal injury during HIV-1-associated dementia. J Leukoc Biol 68:413-422.

Petito CK and Cash KS (1992). Blood-brain barrier abnormalities in the acquired immunodeficiency syndrome: immunohistochemical localization of serum proteins in postmortem brain. Ann Neurol 32:658-666.

Poland SD, Rice GP, and Dekaban GA (1995). HIV-1 infection of human brain-derived microvascular endothelial cells in vitro. J Acquir Immune Defic Syndr Hum Retrovirol 8:437445.

Posner MR, Cavacini LA, Emes CL, Power J, and Byrn R (1993). Neutralization of HIV-1 by F105, a human monoclonal antibody to the CD4 binding site of gp120. J Acquir Immune Defic Syndr 6:7-14.

Power C, Kong PA, Crawford TO, Wesselingh S, Glass JD, McArthur JC, and Trapp BD (1993). Cerebral white matter changes in acquired immunodeficiency syndrome dementia: Alterations of the blood-brain barrier. Ann Neurol 34:339350.

Prasadarao NV, Wass CA, Hacker J, Jann K, and Kim KS (1993). Adhesion of S-fimbriated Escherichia coli to brain glycolipids mediated by sfaA gene-encoded protein of S-fimbriae. J Biol Chem 268:10356-10363.

Ren Z, Yao Q, and Chen C (2002). HIV-1 envelope glycoprotein 120 increases intercellular adhesion molecule-1 expression by human endothelial cells. Lab Invest 82:245-255.

Rhodes RH (1991). Evidence of serum-protein leakage across the blood-brain barrier in the acquired immunodeficiency syndrome. J Neuropathol Exp Neurol 50:171-183.

Rieckmann P, Nunke K, Burchhardt M, Albrecht M, Wiltfang J, Ulrich M, and Felgenhauer K (1993). Soluble intercellular adhesion molecule-1 in cerebrospinal fluid: An indicator for the inflammatory impairment of the blood-cerebrospinal fluid barrier. J Neuroimmunol 47:133-140.

Rolinski B, Geier SA, Sadri I, Klauss V, Bogner JR, Ehrenreich $H$, and Goebel FD (1994). Endothelin-1 immunoreactivity in plasma is elevated in HIV-1 infected patients with retinal microangiopathic syndrome. Clin Invest 72:288-293.

Sasseville VG, Newman WA, Lackner AA, Smith MO, Lausen NC, Beall D, and Ringler DJ (1992). Elevated vascular cell adhesion molecule-1 in AIDS encephalitis induced by simian immunodeficiency virus. Am J Pathol 141:1021-1030.
Schecter AD, Berman AB, Yi L, Mosoian A, McManus CM, Berman JW, Klotman ME, and Taubman MB (2001). HIV envelope gp120 activates human arterial smooth muscle cells. Proc Natl Acad Sci USA 98:10142-10147.

Scheglovitova O, Scanio V, Fais S, Papadia S, Abbate I, Castilletti C, Dianzani F, and Capobianchi MR (1995). Antibody to ICAM-1 mediates enhancement of HIV-1 infection of human endothelial cells. Arch Virol 140:951-958.

Schreiber E, Matthias P, Muller MM, and Schaffner W (1989). Rapid detection of octamer binding proteins with 'miniextracts,' prepared from a small number of cells. Nucleic Acids Res 17:6419.

Schved JF, Gris JC, Arnaud A, Martinez P, Sanchez N, Wautier JL, and Sarlat C (1992). von Willebrand factor antigen, tissue-type plasminogen activator antigen, and risk of death in human immunodeficiency virus 1-related clinical disease: Independent prognostic relevance of tissue-type plasminogen activator. J Lab Clin Med 120:411-419.

Seigneur M, Constans J, Blann A, Renard M, Pellegrin JL, Amiral J, Boisseau M, and Conri C (1997). Soluble adhesion molecules and endothelial cell damage in HIV infected patients. Thromb Haemost 77:646-649.

Seilhean D, Dzia-Lepfoundzou A, Sazdovitch V, Cannella B, Raine CS, Katlama C, Bricaire F, Duyckaerts C, and Hauw JJ (1997). Astrocytic adhesion molecules are increased in HIV1 -associated cognitive/motor complex. Neuropathol Appl Neurobiol 23:83-92.

Shrikant P, Benos DJ, Tang LP, and Benveniste EN (1996). HIV glycoprotein 120 enhances intercellular adhesion molecule-1 gene expression in glial cells. Involvement of Janus kinase/signal transducer and activator of transcription and protein kinase C signaling pathways. J Immunol 156: 1307-1314.

Stins MF, Gilles F, and Kim KS (1997). Selective expression of adhesion molecules on human brain microvascular endothelial cells. J Neuroimmunol 76:81-90.

Stins MF, Shen Y, Huang SH, Gilles F, Kalra VK, and Kim KS (2001). Gp120 activates children's brain endothelial cells via CD4. J Neurovirol 7:1-10.

Tamamura H, Omagari A, Hiramatsu K, Gotoh K, Kanamoto $\mathrm{T}, \mathrm{Xu} \mathrm{Y}$, Kodama E, Matsuoka M, Hattori T, Yamamoto N, Nakashima H, Otaka A, and Fujii N (2001). Development of specific CXCR4 inhibitors possessing high selectivity indexes as well as complete stability in serum based on an anti-HIV peptide T140. Bioorg Med Chem Lett 11:1897-1902.

Toneatto S, Finco O, van der PH, Abrignani S, and Annunziata $P$ (1999). Evidence of blood-brain barrier alteration and activation in HIV-1 gp120 transgenic mice. AIDS 13:23432348.

Ugen KE (1993). Generation of antibodies against the aminoterminus of gp120 that elicit antibody-dependent cellular cytotoxicity. In: Refaeli Y, Ziegner U, Agadyanan M, Satre MA, Srikantan V, Wang B, Sato A, Williams WV, and Weiner DB, editors. Vaccines 93. Cold Spring Harbor, NY: Cold Spring Harbor Laboratory, 215-221.

Ullrich CK, Groopman JE, and Ganju RK (2000). HIV-1 gp120- and gp160-induced apoptosis in cultured endothelial cells is mediated by caspases. Blood 96:1438-1442.

van de SA and van der Saag PT (1996). Intercellular adhesion molecule-1. J Mol Med 74:13-33. 
Wahl LM, Corcoran ML, Pyle SW, Arthur LO, Harel-Bellan A, and Farrar WL (1989). Human immunodeficiency virus glycoprotein (gp120) induction of monocyte arachidonic acid metabolites and interleukin 1. Proc Natl Acad Sci USA 86:621625.

Wang ZX, Berson JF, Zhang TY, Cen YH, Sun Y, Sharron M, Lu ZH, and Peiper SC (1998). CXCR4 sequences involved in coreceptor determination of human immunodeficiency virus type-1 tropism. Unmasking of activity with M-tropic Env glycoproteins. J Biol Chem 273:15007-15015.

Weis S, Haug $\mathrm{H}$, and Budka $\mathrm{H}$ (1996). Vascular changes in the cerebral cortex in HIV-1 infection. I. A morphometric investigation by light and electron microscopy. Clin Neuropathol 15:361-366.
Wong D and Dorovini-Zis K (1992). Upregulation of intercellular adhesion molecule-1 (ICAM-1) expression in primary cultures of human brain microvessel endothelial cells by cytokines and lipopolysaccharide. J Neuroimmunol 39:1121.

Wu L, Paxton WA, Kassam N, Ruffing N, Rottman JB, Sullivan N, Choe H, Sodroski J, Newman W, Koup RA, and Mackay CR (1997). CCR5 levels and expression pattern correlate with infectability by macrophage-tropic HIV-1, in vitro. J Exp Med 185:1681-1691. 